\title{
A comparison of robotic arm versus gantry linear accelerator stereotactic body radiation therapy for prostate cancer
}

This article was published in the following Dove Press journal:

Research and Reports in Urology

18 August 2016

Number of times this article has been viewed

\author{
Vladimir Avkshtol \\ Yanqun Dong \\ Shelly B Hayes \\ Mark A Hallman \\ Robert A Price \\ Mark L Sobczak \\ Eric M Horwitz* \\ Nicholas G Zaorsky* \\ Department of Radiation Oncology, \\ Fox Chase Cancer Center, \\ Philadelphia, PA, USA \\ *These authors contributed equally to \\ this work
}

Correspondence: Nicholas G Zaorsky Department of Radiation Oncology, Fox Chase Cancer Center, 333 Cottman Avenue, Philadelphia, PA I9III, USA

$\mathrm{Tel}+\mathrm{I} 215728258 \mathrm{I}$

Fax +12152144038

Email nicholaszaorsky@gmail.com
Abstract: Prostate cancer is the most prevalent cancer diagnosed in men in the United States besides skin cancer. Stereotactic body radiation therapy (SBRT; 6-15 Gy per fraction, up to 45 minutes per fraction, delivered in five fractions or less, over the course of approximately 2 weeks) is emerging as a popular treatment option for prostate cancer. The American Society for Radiation Oncology now recognizes SBRT for select low- and intermediate-risk prostate cancer patients. SBRT grew from the notion that high doses of radiation typical of brachytherapy could be delivered noninvasively using modern external-beam radiation therapy planning and delivery methods. SBRT is most commonly delivered using either a traditional gantry-mounted linear accelerator or a robotic arm-mounted linear accelerator. In this systematic review article, we compare and contrast the current clinical evidence supporting a gantry vs robotic arm SBRT for prostate cancer. The data for SBRT show encouraging and comparable results in terms of freedom from biochemical failure ( $>90 \%$ for low and intermediate risk at $5-7$ years) and acute and late toxicity ( $<6 \%$ grade $3-4$ late toxicities). Other outcomes (eg, overall and cancer-specific mortality) cannot be compared, given the indolent course of low-risk prostate cancer. At this time, neither SBRT device is recommended over the other for all patients; however, gantry-based SBRT machines have the abilities of treating larger volumes with conventional fractionation, shorter treatment time per fraction $(\sim 15$ minutes for gantry vs $\sim 45$ minutes for robotic arm), and the ability to achieve better plans among obese patients (since they are able to use energies $>6$ MV). Finally, SBRT (particularly on a gantry) may also be more cost-effective than conventionally fractionated external-beam radiation therapy. Randomized controlled trials of SBRT using both technologies are underway.

Keywords: prostate cancer, stereotactic body radiation therapy, technology, quality of life

\section{Introduction}

Prostate cancer is the most prevalent cancer diagnosed in men in the United States aside from skin cancer. ${ }^{1}$ Radiation options for prostate cancer include external-beam radiation therapy (EBRT) and brachytherapy $(\mathrm{BT}) .^{2}$ Most men who undergo EBRT are treated with conventionally fractionated RT (CFRT; 1.8-2 Gy per fraction, 15 minutes per day, 5 days per week, for approximately 8 weeks, to a total dose of 76-80 Gy).

Due to the prolonged treatment course, short-duration therapies that provide comparable disease-control rates are drawing interest as alternatives to CFRT. Advances in technology have allowed for the safe delivery of higher doses per fraction, ie, hypofractionated RT (HFRT; 2.1-3.5 Gy per fraction, 15 minutes per day, 5 days per week, for approximately 4 weeks) $)^{3}$ and stereotactic body RT (SBRT, for five fractions of 
Table I Advantages and disadvantages of various forms of RT for prostate cancer

\begin{tabular}{|c|c|c|c|}
\hline Modality & $\begin{array}{l}\text { Machines for RT } \\
\text { delivery }\end{array}$ & Advantages & Disadvantages \\
\hline $\begin{array}{l}\text { CFRT, I.8-2 Gy per } \\
\text { fraction, } 5 \text { days/week, } \\
\sim 8 \text { weeks }\end{array}$ & $\begin{array}{l}\text { Gantry LINAC } \\
\text { Helical tomotherapy }\end{array}$ & $\begin{array}{l}\text { Radiosensitization of tumor cells through } \\
\text { redistribution, reoxygenation, and repair } \\
\text { of sublethal damage in normal tissue } \\
\text { Improves biochemical control in } \\
\text { studies }^{31-36}\end{array}$ & $\begin{array}{l}\text { Up to } 45 \text { treatments over } 9 \text { weeks } \\
\text { QOL: early rectal toxicity commonly seen; late rectal, } \\
\text { urinary, sexual toxicity sometimes seen } \\
\text { Higher cost secondary to protracted treatment delivery, } \\
\text { which builds cost with the delivery of each fraction }{ }^{60}\end{array}$ \\
\hline $\begin{array}{l}\text { HFRT, } 2.1-3.5 \text { Gy per } \\
\text { fraction, } 5 \text { days/week, } \\
\sim 4 \text { weeks }^{3}\end{array}$ & $\begin{array}{l}\text { Gantry LINAC } \\
\text { Helical tomotherapy }\end{array}$ & $\begin{array}{l}\text { Potentially increased radiobiological } \\
\text { efficacy and decreased normal tissue } \\
\text { toxicity } \\
\text { Shorter treatment-delivery time } \\
\text { compared to CFRT }\end{array}$ & $\begin{array}{l}\text { Initial prospective trials inconclusive regarding efficacy } \\
\text { QOL outcomes: inconclusive, with some studies } \\
\text { showing increased toxicity and others showing } \\
\text { decreased toxicity compared to CFRT } \\
\text { Modern prospective trials ongoing }\end{array}$ \\
\hline $\begin{array}{l}\text { SBRT, 6-15 Gy per } \\
\text { fraction, five fractions, } \\
\text { over } \sim 2 \text { weeks }\end{array}$ & $\begin{array}{l}\text { Gantry LINAC } \\
\text { Robotic arm LINAC } \\
\text { Helical tomotherapy }\end{array}$ & Lower cost compared to CFRT & $\begin{array}{l}\text { No long-term data available } \\
\text { Mostly single-institution experiences } \\
\text { Mostly limited to low-risk patients }\end{array}$ \\
\hline
\end{tabular}

Abbreviations: CFRT, conventionally fractionated radiation therapy; HFRT, hypofractionated radiation therapy; LINAC, linear accelerator; SBRT, stereotactic body radiation therapy; QOL, quality of life; RT, radiation therapy.

6-15 Gy per fraction lasting up to 45 minutes per day, one to five treatments, over the course of approximately 2 weeks). ${ }^{4}$ For reference, the relative benefits and risks of EBRT types are listed in Table 1.

SBRT is commonly delivered using a traditional linear accelerator (LINAC; ie, with a gantry) or a robotic arm (ie, CyberKnife $^{\circledR}$; Accuray Incorporated, Sunnyvale, CA, USA). We provide a comparative review of the current clinical evidence behind gantry vs robotic arm SBRT for prostate cancer. First, we review the radiobiology, physics, patient perspective, and resource-allocation considerations behind each technology. Second, we compare published diseasecontrol outcomes and toxicities. Finally, we discuss the future of these technologies, as well as clinical trials on the horizon. For reference, the dose fractionations and sample treatment plans for CFRT, gantry SBRT, robotic arm SBRT, and high-dose-rate BT (HDR-BT) are illustrated in Figure 1.

\section{Materials and methods}

We defined the inclusion criteria for this literature search using the PICOS (population, intervention, control, outcome, study design) approach (Table S1). We conducted a systematic search using the Preferred Reporting Items for Systematic Reviews and Meta-Analyses (PRISMA) literature-selection process (Figure S1). ${ }^{5}$ We searched the published English-language medical literature from 1970 to 2015 in Medline and PubMed using the terms "prostate cancer", AND "stereotactic body radiation therapy", OR "CyberKnife". We searched through reference lists of identified papers for further leads. Limitations of the PICOS/ PRISMA method include the lack of individual patient data, the limited number of studies published, the relative differences in patient staging (eg, low-, intermediate-, and high-risk groups), the multiple methods of RT delivery (ie, gantry vs robotic arm and also differences in image guidance), differences in follow-up time (eg, 2-7 years median), and differences in reporting on outcomes (eg, biochemical failure [BF] differences at different time points).

Notably, other technologies may be used to deliver SBRT, including tomotherapy ${ }^{6}$ and protons. ${ }^{7}$ However, there were no articles identified in our PICOS/PRISMA selection criteria where these devices were solely used to deliver SBRT for prostate cancer. Instead, some patients within other studies may have been treated with the technologies. Therefore, we were unable to evaluate them fairly versus more conventional devices (ie, gantry-based LINACs with photons and robotic arm photons [ie, CyberKnife]), and we excluded them from the analysis. We mention that these devices may be used to deliver SBRT in the Discussion section of the paper, and how they may be used in clinical trials evaluating SBRT.

After identifying full-text articles, we excluded articles focusing on HDR-BT, treatment with tomotherapy SBRT, SBRT as a boost, SBRT as adjuvant treatment, and nonlocalized prostate cancer. We then further excluded articles that did not have disease-control data or had less than a 30-month median follow-up. We included studies that gave androgen-deprivation therapy. The search and screening yielded three gantry-SBRT publications $^{8-10}$ and eleven robotic arm-SBRT publications ${ }^{11-24}$ (Table 2). Patients were organized by risk-group classification from the studies, namely, the National Comprehensive Cancer Network (NCCN) criteria, the preferred staging system. ${ }^{25}$

There were more studies identified where patients were treated with robotic arm LINAC SBRT. Additionally, there were more patients with high-risk disease who were treated on a robotic arm LINAC. This difference comes principally from the history of the evolution of the technologies, and 


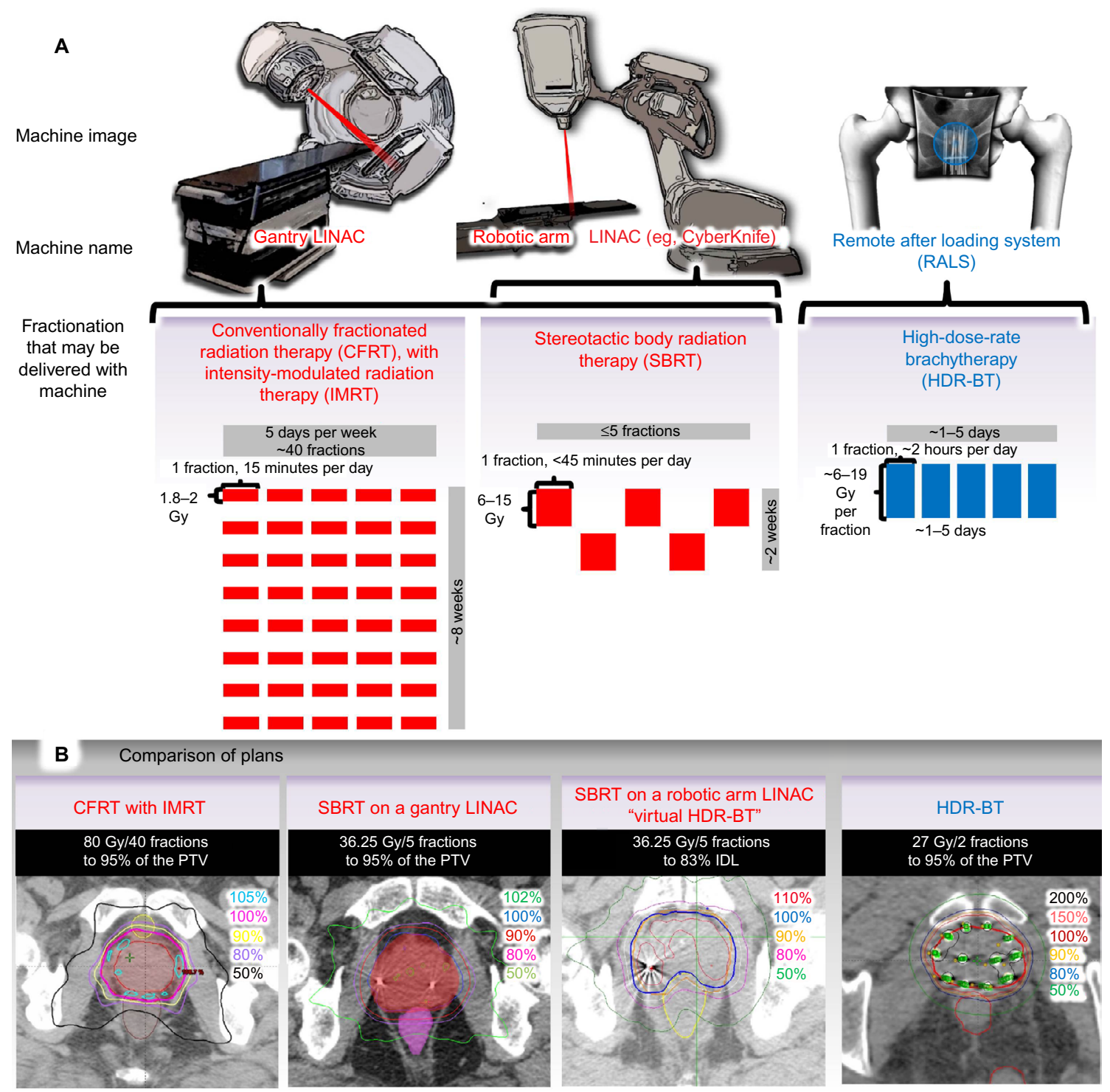

Figure I Dose fraction and treatment plans for different radiation techniques for prostate cancer.

Notes: (A) Three principal types of radiation therapy-fractionation schemes are available: I) CFRT, at I.8-2 Gy fraction, 5 days/week, for approximately 8 weeks; 2) SBRT, at 3.5-15 Gy fraction, up to five treatments over $\sim 2$ weeks (delivered on either a gantry or a robotic arm); and 3) HDR-BT, defined as $\geq 12$ Gy/hour, delivered via a remote afterloading system. Robotic arm SBRT can noninvasively achieve similar dose distributions to HDR, and thus it has been marketed as "virtual HDR-BT". (B) Treatment plans for the four principal types of radiation techniques are displayed. The middle plans are from a gantry LINAC and robotic arm LINAC. Figure adapted from: Meng MB, Wang HH, Zaorsky NG, et al. Clinical evaluation of stereotactic radiation therapy for recurrent or second primary mediastinal lymph node metastases originating from non-small cell lung cancer. Oncotarget. 2015;20;6(17): 15690-15703..$^{83}$ Zaorsky NG, Den RB, Doyle LA, Dicker AP, Hurwitz MD. Combining theoretical potential and advanced technology in highdose rate brachytherapy boost therapy for prostate cancer. Expert Rev Med Devices. 20I 3; I0(6):75I-763. ${ }^{84}$ Zaorsky NG, Shaikh T, Murphy CT, et al. Comparison of outcomes and toxicities among radiation therapy treatment options for prostate cancer. Cancer Treat Rev. 2016;48:50-60. ${ }^{27}$ Wang HH, Zaorsky NG, Meng MB et al. Stereotactic radiation therapy for oligometastases or oligorecurrence within mediastinal lymph nodes. Oncotarget. Epub 2016 Feb $23 .^{85}$ Figures courtesy of Nicholas G Zaorsky.

Abbreviations: HDR, high-dose-rate; IDL, isodose line; LINAC, linear accelerator; PTV, planning target volume.

the subsequent differences in how the technologies were integrated among different hospitals. ${ }^{26,27}$ When the robotic arm LINAC was first introduced in 2001, it was purported to be a "virtual HDR-BT": it was designed to deliver the doses of HDR-BT noninvasively. ${ }^{7,23,28-30}$ Following this promotion, most centers delivering SBRT for prostate cancer started to use the robotic arm LINAC. Nonetheless, gantry-based LINACs may also be used for prostate SBRT. In the 15 years that followed since the inception of the robotic arm LINAC, more patients were treated on the robotic arm LINAC, which accounts for the larger number of patients and more patient heterogeneity among the gantry-based LINAC studies.

Notably, high-risk patients, either with high-grade or bulky (ie, T3-T4 disease), were not typically treated with SBRT. ${ }^{31}$ Nonetheless, these patients may still benefit from the local tumor control of SBRT with either technology. For patients with high-grade (ie, Gleason 8+) tumors, the current focus is the use of systemic therapy (eg, with novel antiandrogens). ${ }^{32}$ For patients with bulky disease, SBRT is avoided, given the concerns for increased toxicity. 
Table 2 SBRT for prostate cancer with at least 30-month follow-up

\begin{tabular}{|c|c|c|c|c|c|c|c|c|c|c|c|c|}
\hline \multirow[t]{2}{*}{ Study } & \multirow[t]{2}{*}{ Phase } & \multirow[t]{2}{*}{$\begin{array}{l}\text { Patients } \\
\text { (n) }\end{array}$} & \multirow[t]{2}{*}{$\begin{array}{l}\text { Risk } \\
\text { group }\end{array}$} & \multirow[t]{2}{*}{$\begin{array}{l}\text { Median } \\
\text { FU } \\
\text { (months) }\end{array}$} & \multirow[t]{2}{*}{$\begin{array}{l}\text { Total } \\
\text { dose } \\
\text { (Gy) }\end{array}$} & \multirow[t]{2}{*}{$\begin{array}{l}\text { Total } \\
\text { fractions }\end{array}$} & \multirow[t]{2}{*}{$\begin{array}{l}\text { Gy per } \\
\text { fraction }\end{array}$} & \multirow[t]{2}{*}{$\begin{array}{l}\text { BED (Gy) } \\
\text { at } \alpha / \beta \text { of } \\
1.5 \text { (for } \\
\text { TC) }\end{array}$} & \multirow[t]{2}{*}{$\begin{array}{l}\text { BED } \\
\text { (Gy) at } \\
\alpha / \beta \text { of } 3.0 \\
\text { (for LT) }\end{array}$} & \multirow[t]{2}{*}{ Actuarial FFBF } & \multicolumn{2}{|c|}{$\begin{array}{l}\text { RTOG/ } \\
\text { CTCAE } \\
\text { late toxicity } \\
\text { grade } \geq 2 \text { (\%) }\end{array}$} \\
\hline & & & & & & & & & & & GU & GI \\
\hline \multicolumn{13}{|l|}{ Gantry } \\
\hline Madsen et $\mathrm{al}^{8}$ & $\mathrm{I} / \mathrm{II}$ & 40 & $\mathrm{~L}$ & 41 & 33.5 & 5 & 6.7 & 156 & 82 & 2 years: $90 \%$ & 20 & 7.5 \\
\hline Loblaw et $\mathrm{al}^{9}$ & $\mathrm{I} / \mathrm{II}$ & 84 & L & 55 & 35 & 5 & 7 & 170 & 89 & 5 years: $98 \%$ & 5 & 8 \\
\hline Mantz $^{10}$ & II & 102 & L & 60 & 40 & 5 & 8 & 221 & 115 & 5 years: $100 \%$ & NR & NR \\
\hline \multicolumn{13}{|l|}{ Robotic arm } \\
\hline Friedland et al" & NA & 112 & L, I, H & 48 & 35 & 5 & 7 & 170 & 89 & 3 years: $97 \%$ & NR & $N R$ \\
\hline \multirow[t]{2}{*}{ Katz et al ${ }^{12,13}$} & $\mathrm{I} / \mathrm{II}$ & 50 & L, I, H & 40 & 35 & 5 & 7 & 170 & 89 & 4 years: $98.5 \%$ & 7.8 & 4.2 \\
\hline & & 254 & & & 36.3 & 5 & 7.3 & 182 & 95 & $93 \%, 75 \% c$ & & \\
\hline \multirow[t]{3}{*}{ Kang et $\mathrm{al}^{1 / 4}$} & NA & 5 & L, I, H & 40 & 32 & 4 & 8 & 179 & 93 & 5 years: $100 \%$ & 6.8 & II \\
\hline & & 28 & & & 34 & 4 & 8.5 & 201 & 105 & $100 \%, 90.8 \%$ & & \\
\hline & & 11 & & & 36 & 4 & 9 & 225 & 117 & & & \\
\hline \multirow[t]{3}{*}{ McBride et $\mathrm{al}^{15}$} & 1 & 10 & $\mathrm{~L}$ & 45 & 37.5 & 5 & 7.5 & 195 & 101 & 3 years: $98 \%$ & 19.2 & 12 \\
\hline & & 34 & & & 36.3 & 5 & 7.3 & 182 & 95 & & & \\
\hline & & 1 & & & NA & & & & & & & \\
\hline \multirow[t]{2}{*}{ King et $\mathrm{al}^{16}$} & II & 16 & L & 32 & 36.3 & 5 & 7.3 & 182 & 95 & 4 years: $94 \%$ & 8.7 & 2 \\
\hline & & 41 & & & 36.3 & 5 & 7.3 & 182 & 95 & & & \\
\hline King et al $\left.\right|^{17,18, \mathrm{~b}}$ & II & 1,100 & L, I, H & 36 & $35-40$ & $4-5$ & NA & NA & NA & $\begin{array}{l}5 \text { years: } 93 \% \\
(95 \%, 84 \%, 81 \%)^{c}\end{array}$ & NR & $N R$ \\
\hline Bolzicco et al ${ }^{19}$ & II & 100 & $\mathrm{~L}, \mathrm{I}, \mathrm{H}$ & 36 & 35 & 5 & 7 & 170 & 89 & 3 years: $94.4 \%$ & 4 & 1 \\
\hline Katz and & Ret & 154 & $\mathrm{~L}, \mathrm{I}$ & 72 & 35 & 5 & 7 & 170 & 89 & 7 years: $93.7 \%$ & NR & $N R$ \\
\hline \multirow[t]{3}{*}{ Kang ${ }^{20,21, \mathrm{~b}}$} & & 323 & & & 36.3 & 5 & 7.3 & 182 & 95 & $(95.6 \%, 89.6 \%)^{c}$ & & \\
\hline & Ret & 158 & L, I, H & 72 & 35 & 5 & 7 & 170 & 89 & 7 years: $95.8 \%$ & 10.9 & 4.1 \\
\hline & & 357 & & & 36.3 & 5 & 7.3 & 182 & 95 & $89.3 \%, 68.5 \% c$ & & \\
\hline Fuller et $\mathrm{a}^{22}$ & II & 53 & $\mathrm{~L}, \mathrm{I}$ & 60 & 38 & 4 & 9.5 & 250 & 130 & 5 years: $100 \%, 92 \%^{\mathrm{c}}$ & 15 & 1 \\
\hline Lee et $\mathrm{al}^{23}$ & Ret & 29 & $\mathrm{~L}, \mathrm{I}, \mathrm{H}$ & 41 & $35-37.5$ & 5 & NA & NA & NA & 4 years: $92.8 \%$ & 6 & 0 \\
\hline \multirow[t]{3}{*}{ Bernetich et $\mathrm{a}^{24}$} & Ret & 5 & L, I, H & 38 & 35 & 5 & 7 & 170 & 89 & 5 years: & 16 & 3 \\
\hline & & 107 & & & 36.3 & 5 & 7.3 & 182 & 95 & $92.7 \%(94.4 \%$ & & \\
\hline & & 30 & & & 37.5 & 5 & 7.5 & 195 & 101 & $94.2 \%, 83.9 \%)^{c}$ & & \\
\hline
\end{tabular}

Notes: 'Listed as overall FFBF or for low-, intermediate-, and high-risk groups; bat least some data published previously. 'For actuarial FFBF, low, intermediate, and high risk group data shown as separate values if available. The $\alpha / \beta$ ratio provides an estimate of the radiosensitivity of cells.

Abbreviations: BED, biological equivalent dose; CTCAE, Common Terminology Criteria for Adverse Events; FFBF, freedom from biochemical failure; FU, follow-up; GI, gastrointestinal; GU, genitourinary; H, high; I, intermediate; L, low; LT, late toxicity; NA, not applicable; NR, not reported; Ret, retrospective; RTOG, Radiation Therapy Oncology Group; SBRT, stereotactic body radiation therapy; TC, tumor control.

\section{Theoretical benefits of robotic arm vs gantry SBRT Radiobiology}

Fractionation has several theoretical radiobiological advantages, including repair, redistribution, and reoxygenation. The basis of fractionation is that dividing a dose into several fractions increases damage to the cancer cells because of reoxygenation of hypoxic tumors and redistribution of cells into radiosensitive phases of the cycle, while at the same time allowing the normal tissues to repair sublethal damage between fractions. However, CFRT has limitations as a treatment modality, including a relatively long treatment course and possible genitourinary (GU) and gastrointestinal (GI) toxicities. ${ }^{33}$ Dose escalation, which has been shown in multiple studies to improve biochemical control, results in an increased rate of toxicity and in further protracted treatment. ${ }^{34-39}$
Hypothetically, SBRT should increase tumor-cell death and decrease radiation-related toxicity compared to CFRT by improving the therapeutic ratio. Typically, as the total RT dose delivered increases, the number of surviving cells decreases. However, the benefits of a higher dose are countered by the increased toxicity to the surrounding normal tissue. The $\alpha / \beta$ ratio is used to approximate the effects of radiation on different tissues and to compare various dose/ fractionation schemes. The $\alpha / \beta$ ratio is thought to be $>10$ Gy for early responding tissues, including skin, mucosa, and most malignant tumors. The $\alpha / \beta$ ratio is thought to be around 3-5 Gy for late-responding tissues, including connective tissues and muscles. Clinical radiobiological models suggest that prostate cancer has a low $\alpha / \beta$ ratio $(\sim 1.5)$, unlike most other malignancies..$^{40}$ The low $\alpha / \beta$ ratio means that prostate cancer cells should be more sensitive to radiation when the dose is delivered in large fraction sizes ${ }^{41}$ The biologically 


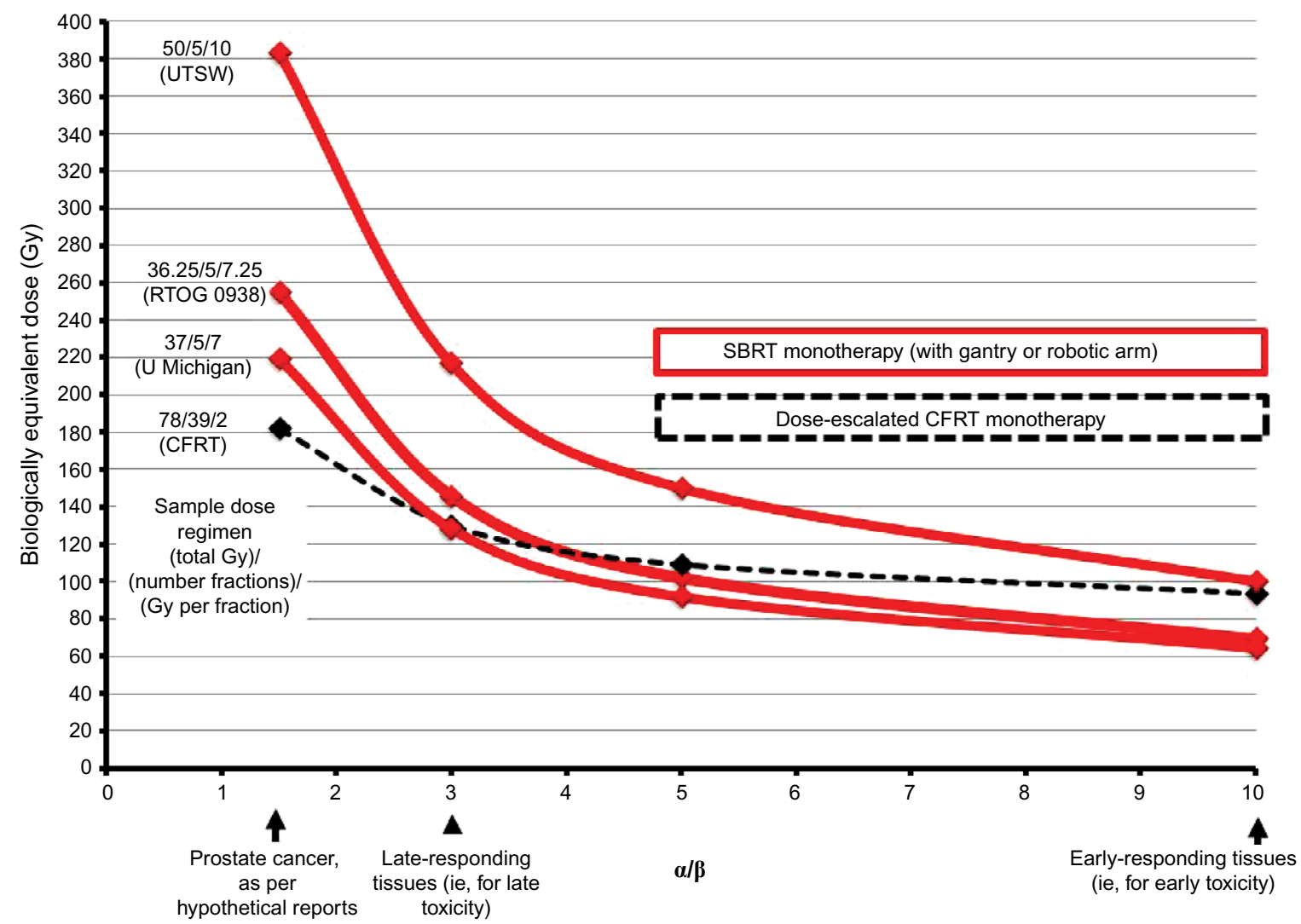

Figure 2 Biologically equivalent dose vs $\alpha / \beta$ ratio for various EBRT-fractionation regimens.

Notes: The BEDs for several clinical trials mentioned (solid red line) compared to the regimen of dose-escalated CFRT monotherapy (dashed black line). SBRT (vs CFRT) allows for a higher BED at $\alpha / \beta$ of 1.5 (for prostate cancer) than at $\alpha / \beta$ of 3 (for late toxicity), thereby increasing the therapeutic ratio. The $\alpha / \beta$ ratio provides an estimate of the radiosensitvity of cells. Radiobiological models based on clinical data suggest that prostate cancer has a low $\alpha / \beta$ ratio of $\sim 1.5 \mathrm{~Gy}$, implying that prostate cancer cells are more sensitive to doses delivered in larger fraction size. This value is lower than the 3 Gy estimated for late-responding tissues (eg, bladder/rectal mucosa, muscles). If the $\alpha / \beta$ ratio for the tumor is lower than that for the normal tissues, increasing the dose per fraction would increase the BED for the tumor more than the BED for the normal tissues, and the therapeutic ratio would be improved.

Abbreviations: BED, biologically equivalent dose; CFRT, conventionally fractionated radiation therapy; SBRT, stereotactic body radiation therapy; RTOG, Radiation Therapy Oncology Group; U Michigan, University of Michigan; UTSW, University of Texas Southwestern Medical Center.

equivalent dose (BED) formula explains the sensitivity to the larger fraction size:

$$
\mathrm{BED}=(n d[1+d /\{\alpha / \beta\}])
$$

In this formula, $\mathrm{n}$ is the number of radiation fractions and $\mathrm{d}$ is dose size per fraction.

If the $\alpha / \beta$ ratio for the tumor is lower than that for the surrounding tissues, as hypothesized for prostate cancer, increasing the dose per fraction increases the BED more for the tumor than for the normal tissues. ${ }^{7}$ The diverging BED values result in an increase in the therapeutic ratio. ${ }^{42,43}$ Sample BED curves for $\alpha / \beta$ ratios of $1.5-10$ Gy for some of the SBRT regimens referenced in this review are juxtaposed with a CFRT schedule in Figure 2. The total BEDs of various SBRT fractionations (at $\alpha / \beta$ ratios of 1.5 and 3 ) are listed in Table 2 .

The BED is not an exact predictor of efficacy or toxicity. The BED does not take into account all methods of cancercell death (eg, lipid-membrane phosphorylation). ${ }^{44}$ There is also growing evidence that higher doses per fraction cause indirect tumor death by causing vascular damage through ceramide-mediated apoptosis of endothelial cells and creating an unviable environment for the cancer. Looking at only such tumor-cell characteristics as the BED would not address the effect of RT on the nearby vasculature, and would not fully explain the efficacy of SBRT treatment. ${ }^{45}$ Also, the optimal overall time to deliver a dose of SBRT is unclear. An analysis by Thames et al revealed a relative increase of $6 \%$ in BFs for a 1-week increase in overall time at 5-year follow-up, suggesting that outcomes may be improved by decreasing treatment time. ${ }^{46}$ Additionally, the BED does not take into account how the dose is prescribed: actual intratumoral BED increases when the dose is prescribed to a point versus to a volume versus to an isodose line (sorted by increasing intratumoral BED). The dose distribution also plays a role in RT's effect on normal tissues.

SBRT has become increasingly popular since the 2000s, and since its inception, it has been marketed as a noninvasive alternative to HDR-BT., ${ }^{4,47}$ EBRT and BT have different 
dosimetric characteristics in terms of conformity and heterogeneity, as well as normal-tissue sparing (shown in Figure 1). For example, for BT, there is greater dose heterogeneity, with higher dose regions near the catheters, ${ }^{37}$ whereas with EBRT the dose is generally more homogeneous. ${ }^{29}$ There is currently no evidence that gantry or robotic arm SBRT provides a more favorable BED for the tumor while lowering the BED to the normal tissues. As a result, both delivery systems should benefit similarly from this radiobiological therapeutic advantage.

\section{Physics}

Both robotic arm and gantry SBRT employ cutting-edge image-guidance systems, which allow for the detection and correction of target motion and systematic and random errors during treatment. ${ }^{48}$ Robotic arm SBRT utilizes gold fiducial makers for image guidance, which can limit its use in people who are unwilling to undergo a procedure to place the fiducials. ${ }^{49}$ Gantry SBRT can utilize severe different imaging-guidance modalities, including cone-beam computed tomography $(\mathrm{CT}),{ }^{50}$ radiofrequency transponders (eg, Calypso $\left.{ }^{\circledR}\right),{ }^{51} \mathrm{CT}$ on rails, ${ }^{52}$ or gold fiducial markers. ${ }^{49}$

During robotic arm SBRT, the gold fiducial markers are tracked by a set of orthogonal images taken every 15-30 seconds (or less often, depending upon the amount of target motion), and the robotic arm position adjusts accordingly. ${ }^{21}$ Meanwhile, gantry-based SBRT usually relies on a single snapshot assessment of the prostate position at the beginning of the fraction using cone-beam CT or implanted fiducial markers. There is no continuous imaging during treatment delivery to assess intrafraction prostate motion, leading to greater localization uncertainty during the treatment. This uncertainty led to the development of radiofrequency-emitting transponders (ie, Calypso beacons), which provide real-time interfraction and intrafraction assessment of prostate motion. ${ }^{53}$ If radiofrequency beacons are used for image guidance, the treatment can be paused and the patient repositioned to ensure correct localization within the treatment field. The radiofrequency transponders do come at a monetary cost and require the magnetic resonance imaging simulation to be performed prior to their placement to prevent imaging artifacts from the transponders.

Depending on the image-guided RT method employed, protocol used, and the treating physician's confidence, different planning target volume (PTV) margins are used during prostate SBRT, which could affect the toxicity profile. Almost all SBRT robotic arm studies used a protocol that called for an expansion margin of $5 \mathrm{~mm}$ in all directions except for 3 mm posteriorly. ${ }^{11,13,15,16,18-20,23,24,54,55}$ Two of the studies used smaller expansion margins. The smallest expansion margin was seen in Fuller et al, where an expansion of $2 \mathrm{~mm}$ in all directions except for $0 \mathrm{~mm}$ posteriorly was used in low-risk patients. $^{22}$ In comparison, an ongoing Phase II clinical study from the University of Michigan and a trial by Mantz used PTV margins of $3 \mathrm{~mm}$ and $2 \mathrm{~mm}$, respectively. ${ }^{10,42}$ Both of the studies used radiofrequency beacons for localization and real-time tracking of gantry SBRT. The University of Michigan study contended that when using Calypso to monitor intrafraction translation and rotation, one could safely reduce the PTV to gain a toxicity-profile advantage without the sacrifice of disease control. ${ }^{56}$ The two gantry-SBRT studies that did not use radiofrequency beacons - Madsen et al and Loblaw et al - had larger PTV margins of 4-5 $\mathrm{mm}$ in all directions. ${ }^{8,9}$ Overall, there does not seem to be a consistent difference between the robotic arm and gantry LINACs with respect to PTV margins.

\section{Patient perspective}

The treatment course of SBRT, usually 6 weeks shorter than CFRT, would be more accepted by patients because the length of treatment is the most frequently patient-cited drawback of CFRT. ${ }^{57}$ Along with the inconvenience, there are also outof-pocket costs that the patient must incur with the longer conventional fractionation. Loblaw et al estimated that their five-fraction treatment course saved their patients an average CAD \$1,928 (around USD \$1,522 at the time of writing) for travel, parking, accommodation, and time off work compared to a standard 39-fraction course. ${ }^{9}$

Although both gantry and robotic arm SBRT offer the benefit of a shorter treatment course, gantry SBRT has the advantage of shorter time to deliver each fraction. A typical gantry-arm SBRT fraction for prostate cancer lasts approximately $15 \mathrm{~min}$ utes. The length of treatment is only several minutes longer than CFRT despite the increase in dose per fraction, because gantry delivery time is largely limited by the maximum speed of the multileaf collimator leaves rather than the dose rate. A typical robotic arm treatment, at around 45 minutes, is three times as long. Lying still for such a prolonged period of time can cause significant discomfort for some patients.

\section{Resource allocation}

SBRT can potentially reduce costs compared to CFRT. Calculation models have shown that wage costs outweigh the cost of machines because of the labor-intensive nature of RT planning and delivery. ${ }^{58-62}$ Although the SBRT treatmentplanning cost is high, this cost is only incurred once, at the beginning of treatment. On the other hand, the delivery cost, ie, the cost to run the treatment machine, increases with the number of fractions. ${ }^{63}$ The significant reduction in treatment course afforded by SBRT results in overall savings. The 
mean cost of conventional intensity-modulated RT (IMRT), $\$ 29,356,{ }^{64}$ is higher than the estimated cost of robotic arm SBRT, between $\$ 19,275$ and $\$ 24,873.55,58,65,66$ Parthan et al compared the cost-effectiveness of IMRT with SBRT and proton-beam therapy using the Markov model, assuming equal long-term efficacy. SBRT was more cost-effective in $75 \%$ and $94 \%$ of simulations compared with IMRT and proton-beam therapy, respectively. ${ }^{58}$

The Centers for Medicare \& Medicaid Services also used a Markov model to compare cost effectiveness, but biased its study against SBRT by assuming increased late toxicity from hypofractionation. The study used the 2012 Medicare payment schedule for hospital-based practice to determine the baseline cost of each treatment. Medicare estimated the cost of robotic SBRT and nonrobotic SBRT to be $\$ 19,275.41$ and $\$ 10,108.93$, respectively. ${ }^{67}$ The incremental cost-effectiveness ratio for IMRT over nonrobotic SBRT was $\$ 591,100 /$ quality-adjusted life year. The incremental cost-effectiveness ratio for IMRT over robotic arm SBRT was still in favor of SBRT, at $\$ 285,000$ /quality-adjusted life year, despite almost twice the cost of nonrobotic SBRT. ${ }^{65}$ The difference between gantry and robotic arm SBRT was elucidated by Sharieff et al. They calculated the cost of robotic arm SBRT to be $\$ 6,333$ per patient and gantry-based SBRT to be $\$ 4,368$ per patient. ${ }^{68}$

In practice, a robotic arm SBRT system is typically only used to deliver SBRT, due to its long treatment times, which limit its usefulness for more protracted treatment regimens. Newer multileaf collimator-equipped versions offer the ability to treat larger targets, with the potential to decrease treatment times. A gantry-SBRT platform can be used to deliver SBRT to larger tumors and to deliver IMRT with more protracted regimens as necessary. The use of a gantry system could decrease the number of LINACs that any one department requires, occupy less clinic space, and require less maintenance. Therefore, changing to an SBRT-treatment regimen may decrease the number of work hours and overall cost of treating each patient, especially with gantry SBRT.

\section{Robotic arm and gantry-SBRT efficacy}

The outcomes from several recent SBRT studies are listed in Table $2 .^{8-22}$ The longest published median follow-up time for a robotic arm-based study is 6 years ( 72 months), though this was for a retrospective analysis..$^{20,21}$ The longest follow-up for a gantry-based study was 60 months in a Phase II trial. ${ }^{10}$ The mean follow-up time for robotic arm-based studies and gantry-based studies is 3.7 years ( 44.4 months) and 4.3 years (50.7 months), respectively. Studies using robotic arm SBRT have included a total of 2,463 patients (mean 224 per study) and gantry SBRT studies 226 patients (mean 75 per study).

Freedom from $\mathrm{BF}$ (FFBF) rates for low-risk patients are $\geq 90 \%$ at up to 7 years (range $90 \%-100 \%$ ) for either treatment modality. Most of the FFBF rates for intermediate risk are also $\geq 90 \%$, but two studies with longer follow-up had lower rates $(89.6 \%$ and $84 \%$ at 7 years and 5 years, respectively). ${ }^{18,20,21}$ The high-risk patients had more variability in their FFBF rates, with a range of $68.5 \%-90.8 \%$. For this review article, the gantry-LINAC studies included only lowrisk patients. Only one study using a gantry LINAC included non-low-risk prostate cancer patients; however, this study was excluded from the current review article because some of the patients were treated with tomotherapy SBRT. ${ }^{69}$

There are a number of differences between SBRT studies and those of CFRT or HFRT. First, the follow-up times of gantry and robotic arm studies (mean 3.8 years) are significantly shorter than those of other randomized controlled trials (typically all $>5$ years). ${ }^{3}$ Second, from a historical perspective, there have been many more patients treated with CFRT and HFRT; therefore, these are the current standard-of-care treatment options in the NCCN guidelines. ${ }^{70}$ Third, most of the patients in the presented SBRT trials had low-risk disease. It will be necessary to enroll more intermediate- and high-risk patients to see if they have comparable outcomes.

All RT studies (CFRT, HFRT, SBRT) have used FFBF as the primary outcome measure. FFBF is limited, because the prostate specific antigen may be coming from a distant metastasis and not local failure. ${ }^{61,71}$ Although new imaging modalities (eg, multiparametric magnetic resonance imaging) exist to differentiate normal prostate from local recurrence, many of these are investigational. ${ }^{72}$ For now, the NCCN and American Society for Therapeutic Radiation Oncology have recognized SBRT as a possible treatment option for only low- and intermediate-risk prostate cancer. ${ }^{73,74}$ Ultimately, although the biochemical results of gantry and robotic arm SBRT studies appear promising, a number of issues must be addressed before SBRT can be considered a standard of care and gantry and robotic arm LINACs compared in more detail.

\section{Robotic arm and gantry-SBRT toxicity}

We summarize the late toxicities reported by studies with SBRT in Table 2.8,9,12-16,19,20,22-24 The most common grading 
systems used are the Radiation Therapy Oncology Group (RTOG) toxicity criteria and the Common Terminology Criteria for Adverse Events (CTCAE). RTOG/CTCAE was used in nine of ten studies on robotic arm SBRT and two of two studies on gantry SBRT that reported GI and GU toxicity rates. Some differences between the two grading systems have been recorded. ${ }^{75}$ For the purposes of this article, we provide toxicity rates from either grading system.

For robotic arm-based studies, the rate of late RTOG/ CTCAE GU toxicity grade $\geq 2$ ranged from $4 \%$ to $19.2 \%$, and the rate of late RTOG/CTCAE GI toxicity grade $\geq 2$ ranged from 0 to $12 \%$. Serious late toxicities - RTOG/ CTCAE grade $\geq 3$ - were rare. Serious toxicity rates ranged from 0 to $6 \%$ and 0 to $5 \%$, for GU and GI, respectively. For the two gantry studies by Madsen et al and Loblaw et al, the rates of late RTOG/CTCAE GU toxicity grade $\geq 2$ were $5 \%$ and $20 \%$ and late RTOG/CTCAE GI toxicity grade $\geq 2$ $8 \%$ and $7.5 \%$, respectively. There was only one patient in the gantry-SBRT studies who developed serious late toxicity: he had a history of diverticulitis and developed an anal fistula after radiation. ${ }^{9}$ Overall, GU and GI RTOG/CTCAE toxicities are similar between robotic arm and gantry-based studies. In addition, the toxicity results support the safety of both SBRT-delivery techniques because they are comparable to the large Phase III studies of HFRT and CFRT. Janowski et al treated patients with large prostate volumes, $\geq 50 \mathrm{~cm}^{3}$, with robotic arm SBRT. ${ }^{76}$ GI and GU toxicity rates were comparable, if not better, than those observed in CFRT and BT treatment of large prostates.

There are a number of important caveats to consider when interpreting SBRT toxicities. First, late effects from radiation can occur decades after therapy. ${ }^{77}$ Recent SBRT studies do not have the follow-up data to capture these late side effects like the more established treatment options. ${ }^{39}$ Second, the RTOG toxicity score does not evaluate anorectal symptoms, such as urgency of defecation and fecal incontinence. Detailed qualityof-life measures are generally not included in SBRT studies, as they are for other modalities. Third, the Phase III studies of CFRT included low-, intermediate-, and high-risk groups. The higher-risk disease groups were more likely to have areas outside the prostate, such as seminal vesicles, included in their RT planning. The increased treatment volume outside the prostate would predispose the patients with high-risk disease to higher toxicity. Finally, many of the SBRT studies were single-institution experiences. Consequently, the toxicity results might not be representative of a more diverse patient population. ${ }^{78}$ The limitations mentioned preclude us from fully comparing toxicities between gantry and robotic arm LINACs.
Table 3 Comparison of gantry and robotic arm SBRT for prostate cancer

\begin{tabular}{|c|c|c|}
\hline & Gantry LINAC & Robotic arm LINAC \\
\hline Radiobiology & $\begin{array}{l}\text { Takes advantage of low } \\
\alpha / \beta \text { ratio to increase } \\
\text { therapeutic ratio }\end{array}$ & $\begin{array}{l}\text { Takes advantage of low } \\
\alpha / \beta \text { ratio to increase } \\
\text { therapeutic ratio }\end{array}$ \\
\hline Radiophysics & $\begin{array}{l}\text { CT (CBCT or } \mathrm{CT} \\
\text { on rails), gold fiducial } \\
\text { markers, radiofrequency } \\
\text { beacons } \\
\text { Similar margins around } \\
\text { CTV. Typically 6-15 } \\
\text { MV }^{86}\end{array}$ & $\begin{array}{l}\text { Gold fiducial markers } \\
\text { Similar margins around } \\
\text { CTV } 6 \mathrm{MV} \text { only. Due } \\
\text { to only a lower energy } \\
\text { available, achieving optimal } \\
\text { plans for obese patients } \\
\text { (who are at higher risk of } \\
\text { biochemical failure) may be } \\
\text { difficult }^{86}\end{array}$ \\
\hline $\begin{array}{l}\text { Resource } \\
\text { allocation }\end{array}$ & $\begin{array}{l}\text { Less resource allocation } \\
\text { than IMRT and protons } \\
\text { Less expensive than } \\
\text { robotic arm SBRT } \\
(\$ 10,108.93 \text {, as per } \\
\text { Medicare }) \\
\text { Can be used to deliver } \\
\text { a variety of radiation } \\
\text { techniques }\end{array}$ & $\begin{array}{l}\text { Less resource allocation } \\
\text { than IMRT and protons } \\
\text { More expensive than gantry } \\
\text { SBRT (\$19,275.4I, } \\
\text { as per Medicare) } \\
\text { Typically used only to } \\
\text { deliver SBRT }\end{array}$ \\
\hline $\begin{array}{l}\text { Patient } \\
\text { perspective }\end{array}$ & $\begin{array}{l}\text { Shorter treatment } \\
\text { course than CFRT ( } 2 \\
\text { weeks vs } \sim 8 \text { weeks) } \\
\text { Shorter treatment } \\
\text { time than robotic arm } \\
\text { LINAC ( } 15 \text { minutes vs } \\
\sim 45 \text { minutes })\end{array}$ & $\begin{array}{l}\text { Shorter treatment } \\
\text { course than CFRT ( } 2 \\
\text { weeks vs } \sim 8 \text { weeks }) \\
\text { Longer treatment time } \\
\text { than gantry-based LINAC } \\
(\sim 45 \text { minutes vs } \sim 15 \\
\text { minutes) }\end{array}$ \\
\hline Efficacy & $\begin{array}{l}\text { Early results comparable } \\
\text { to well-established } \\
\text { modalities } \\
\text { Comparable outcomes } \\
\text { between gantry-based and } \\
\text { robotic arm SBRT (5-year } \\
\text { biochemical recurrence- } \\
\text { free survival }>90 \% \text { ) }\end{array}$ & $\begin{array}{l}\text { Early results comparable to } \\
\text { well-established } \\
\text { modalities } \\
\text { Comparable outcomes } \\
\text { between gantry-based and } \\
\text { robotic arm SBRT (5-year } \\
\text { biochemical recurrence- } \\
\text { free survival >90\%) }\end{array}$ \\
\hline Toxicity & $\begin{array}{l}\text { Early results comparable } \\
\text { to well-established } \\
\text { modalities } \\
\text { Comparable outcomes } \\
\text { between gantry-based } \\
\text { and robotic arm SBRT } \\
\text { ( }<6 \% \text { of patients with } \\
\text { RTOG grade } \\
3-4 \text { toxicities) }\end{array}$ & $\begin{array}{l}\text { Early results comparable to } \\
\text { well-established } \\
\text { modalities } \\
\text { Comparable outcomes } \\
\text { between gantry-based } \\
\text { and robotic arm SBRT } \\
\text { (<6\% of patients with } \\
\text { RTOG grade } \\
3-4 \text { toxicities) }\end{array}$ \\
\hline
\end{tabular}

Abbreviations: $\mathrm{CBCT}$, cone-beam computed tomography; CFRT, conventionally fractionated radiation therapy; CT, computed tomography; CTV, clinical target volume; IMRT, intensity-modulated radiation therapy; LINAC, linear accelerator; RTOG, Radiation Therapy Oncology Group; SBRT, stereotactic body radiation therapy.

\section{Future direction}

The advantages and disadvantages of gantry and robotic arm LINACs are illustrated in Table 3. The current data suggest that gantry and robotic arm SBRT are similar in efficacy and toxicity. It is likely due to their similarities that there are no 
Table 4 Current Phase III-IV clinical trials of SBRT for prostate cancer

\begin{tabular}{|c|c|c|c|c|c|c|c|c|c|}
\hline $\begin{array}{l}\text { Clinical trial namel } \\
\text { identifier }\end{array}$ & $\begin{array}{l}\text { Patients } \\
\text { (n) }\end{array}$ & Phase & Risk groups & Treatments & $\begin{array}{l}\mathbf{R T} \\
\text { system }\end{array}$ & $\begin{array}{l}\text { Total dose } \\
\text { (Gy) }\end{array}$ & $\begin{array}{l}\text { Total } \\
\text { fractions }\end{array}$ & $\begin{array}{l}\text { Gy per } \\
\text { fraction }\end{array}$ & Primary outcome \\
\hline NCT0I584258 & 1,716 & III & L, I & SBRT & CK & 36.25 & 5 & 7.25 & FFBF \\
\hline Prostate advances in & & & & RP (laparoscopic) & & & & & \\
\hline comparative evidence & & & & RP (robotic) & & & & & \\
\hline (PACE) & & & & CFRT & G & 78 & 39 & 2 & \\
\hline NCT0I352598 & 30 & IV & L, I & SBRT & NR & $30-40$ & $4-5$ & $6-10$ & FFBF \\
\hline St John's Mercy Research & & & $\mathrm{H}$ & $\mathrm{EBRT}+\mathrm{SBRT}$ & NR & $|9-2|$ & $2-3$ & $6.3-10.5$ & \\
\hline \multicolumn{10}{|l|}{ Institute } \\
\hline ISRCTN4590532I & 592 & III & I & SBRT & NR & 42.7 & 7 & 6.1 & FFBF \\
\hline Scandinavian HYPO & & & & CFRT & & 78 & 39 & 2.0 & \\
\hline NCT0I58I749 & 50 & IV & L, I & SBRT & G & 36.25 & 5 & 7.25 & Acute and late GI/ \\
\hline Main Line Health & & & & & & & & & GU toxicity \\
\hline NCT0I794403 & 75 & III & L, I & SBRT & NR & 36.25 & 5 & 7.25 & Biochemical, clinical, \\
\hline University of Miami & & & & HFRT & G & 70.2 & 26 & 2.7 & or biopsy failure \\
\hline
\end{tabular}

Abbreviations: CFRT, conventionally fractionated radiation therapy; CK, CyberKnife; EBRT, external-beam RT; FFBF, freedom from biochemical failure; G, gantry; GI, gastrointestinal; GU, genitourinary; H, high; HFRT, hypofractionated RT; I, intermediate; L, low; NR, not reported; RP, radical prostatectomy; RT, radiation therapy; SBRT, stereotactic body RT.

ongoing head-to-head trials comparing gantry and robotic arm SBRT in the treatment of prostate cancer. Nevertheless, there are several important active trials looking at SBRT for prostate cancer.

Phase III-IV studies will be necessary to show that SBRT is noninferior to CFRT. The current Phase III-IV trials looking at SBRT for organ-confined prostate cancer are listed in Table 4. The PACE trial has two parallel randomization arms that will compare SBRT to radical prostatectomy in patients who are surgical candidates and SBRT to CFRT in patients who are not surgical candidates. ${ }^{79}$

There are also several ongoing Phase II trials in addition to the Phase III-IV studies. RTOG 0938 is comparing SBRT (36.25 Gy in five fractions over 2 weeks) to HFRT (51.6 Gy delivered in 12 fractions over 2.5 weeks), with the primary outcome being quality of life. ${ }^{55}$ The multiinstitutional study from the University of Michigan on radiofrequency fiducial guided gantry SBRT, delivers 37 Gy over five fractions. The PTV margins are smaller in this trial than RTOG 0938 (3 vs 3-5 mm). This study will help elucidate the toxicity and disease-control rates of gantry-based SBRT with real-time tracking and tighter PTV margins. ${ }^{46}$

Despite the encouraging preliminary results of SBRT for prostate cancer, there is still no consensus regarding the optimal dose and fractionation regimen for gantry and robotic arm SBRT. This makes it difficult to compare SBRT to more established treatment options. The maximum efficacious $\mathrm{BED}$ for prostate cancer is estimated to be $200 \mathrm{~Gy},{ }^{80}$ though most SBRT studies exceed this value (Figure 2). Moreover, an increase in BED and improvement in FFBF may not be associated with improvement in survival. ${ }^{81}$ In the robotic arm studies, the prescription dose ranges from 32 to 40 Gy given in four to five fractions. Katz and Kang, Bernetich et al, and Beckendorf et al found an increase in late GU toxicity in even relatively small changes in total dose. ${ }^{20,21,24,39}$ Similarly, the gantry studies had a wide range of total dose: 33.5-40 Gy. A study from the University of Texas Southwestern Medical Center (UTSW) and the University of Minnesota included prostate cancer patients treated to 45-50 Gy over five fractions. The UTSW study had the highest BED values when compared to the included studies (Figure 2), and one of the highest late grade $\geq 2 \mathrm{GU}$ and GI toxicity rate at $11 \%{ }^{62,69,82}$ The heterogeneity in prescription doses and its relation to toxicity illustrates the need to find an optimal dose that would provide an acceptable toxicity profile without sacrificing disease control.

\section{Conclusion}

SBRT is an increasingly popular radiation-treatment practice that is hypothesized to improve tumor control, increase the therapeutic ratio, improve patient quality of life, and reduce resource consumption compared to CFRT. Our analysis of current clinical data suggests that robotic arm and gantrybased SBRT provide equivalent BF rates and toxicities. Studies included in this analysis were limited by a number of factors, including short follow-up, no report of change in overall or cancer-specific survival, exclusion of intermediate- and high-risk patients, and relatively small number of patients treated. Randomized controlled trials comparing SBRT to CFRT and HFRT using both technologies are underway.

\section{Author contributions}

All authors contributed to the conception and design, analysis, interpretation of data, and drafting and revision for 
important intellectual content of the abstract and manuscript. All authors read and approved the final manuscript and agree to be accountable for all aspects of the work. All figures were created by NGZ.

\section{Disclosure}

The authors report no conflicts of interest in this work.

\section{References}

1. Siegel RL, Miller KD, Jemal A. Cancer statistics, 2015. CA Cancer J Clin. 2015;65(1):5-29.

2. Shen X, Zaorsky NG, Mishra MV, et al. Comparative effectiveness research for prostate cancer radiation therapy: current status and future directions. Future Oncol. 2012;8(1):37-54.

3. Zaorsky NG, Ohri N, Showalter TN, Dicker AP, Den RB. Systematic review of hypofractionated radiation therapy for prostate cancer. Cancer Treat Rev. 2013;39(7):728-736.

4. Zaorsky NG, Studenski MT, Dicker AP, Gomella L, Den RB. Stereotactic body radiation therapy for prostate cancer: is the technology ready to be the standard of care? Cancer Treat Rev. 2013;39(3):212-218.

5. Moher D, Liberati A, Tetzlaff J, Altman DG. Preferred reporting items for systematic reviews and meta-analyses: the PRISMA statement. $J$ Clin Epidemiol. 2009;62(10):1006-1012.

6. Macias VA, Blanco ML, Perez-Romasanta LA. Initial experience with stereotactic body radiation therapy for localized prostate cancer using helical tomotherapy. Clin Transl Oncol. 2014;16(4):380-385.

7. Zaorsky NG, Harrison AS, Trabulsi EJ, et al. Evolution of advanced technologies in prostate cancer radiotherapy. Nat Rev Urol. 2013;10(10):565-579.

8. Madsen BL, Hsi RA, Pham HT, Fowler JF, Esagui L, Corman J. Stereotactic hypofractionated accurate radiotherapy of the prostate (SHARP), $33.5 \mathrm{~Gy}$ in five fractions for localized disease: first clinical trial results. Int J Radiat Oncol Biol Phys. 2007;67(4):1099-1105.

9. Loblaw A, Cheung P, D'Alimonte L, et al. Prostate stereotactic ablative body radiotherapy using a standard linear accelerator: toxicity, biochemical, and pathological outcomes. Radiother Oncol. 2013;107(2):153-158.

10. Mantz C. A phase II trial of stereotactic ablative body radiotherapy for low-risk prostate cancer using a non-robotic linear accelerator and realtime target tracking: report of toxicity, quality of life, and disease control outcomes with 5-year minimum follow-up. Front Oncol. 2014;4:279.

11. Friedland JL, Freeman DE, Masterson-McGary ME, Spellberg DM. Stereotactic body radiotherapy: an emerging treatment approach for localized prostate cancer. Technol Cancer Res Treat. 2009;8(5): 387-392.

12. Katz AJ, Santoro M, Ashley R, Diblasio F, Witten M. Stereotactic body radiotherapy as boost for organ-confined prostate cancer. Technol Cancer Res Treat. 2010;9(6):575-582.

13. Katz AJ, Santoro M, DiBlasio F, Ashley R. Stereotactic body radiation therapy for low-, intermediate- and high-risk prostate cancer: disease control and quality of life. Int J Radiat Oncol Biol Phys. 2011;81:S100.

14. Kang JK, Cho CK, Choi CW, et al. Image-guided stereotactic body radiation therapy for localized prostate cancer. Tumori. 2011;97(1): 43-48.

15. McBride SM, Wong DS, Dombrowski JJ, et al. Hypofractionated stereotactic body radiotherapy in low-risk prostate adenocarcinoma: preliminary results of a multi-institutional phase 1 feasibility trial. Cancer. 2012;118(15):3681-3690.

16. King CR, Brooks JD, Gill H, Presti JC Jr. Long-term outcomes from a prospective trial of stereotactic body radiotherapy for low-risk prostate cancer. Int J Radiat Oncol Biol Phys. 2012;82(2):877-882.

17. King CR, Collins S, Fuller D, et al. Health-related quality of life after stereotactic body radiation therapy for localized prostate cancer: results from a multi-institutional consortium of prospective trials. Int $J$ Radiat Oncol Biol Phys. 2013;87(5):939-945.
18. King CR, Freeman D, Kaplan I, et al. Stereotactic body radiotherapy for localized prostate cancer: pooled analysis from a multi-institutional consortium of prospective phase II trials. Radiother Oncol. 2013;109(2): 217-221.

19. Bolzicco G, Favretto MS, Satariano N, Scremin E, Tambone C, Tasca A. A single-center study of 100 consecutive patients with localized prostate cancer treated with stereotactic body radiotherapy. BMC Urol. 2013;13:49.

20. Katz AJ, Kang J. Quality of life and toxicity after SBRT for organconfined prostate cancer, a 7-year study. Front Oncol. 2014;4:301.

21. Katz AJ, Kang J. Stereotactic body radiotherapy as treatment for organ confined low- and intermediate-risk prostate carcinoma, a 7-year study. Front Oncol. 2014;4:240.

22. Fuller DB, Naitoh J, Mardirossian G. Virtual HDR CyberKnife SBRT for localized prostatic carcinoma: 5-year disease-free survival and toxicity observations. Front Oncol. 2014;4:321.

23. Lee $\mathrm{YH}$, Son $\mathrm{SH}$, Yoon SC, et al. Stereotactic body radiotherapy for prostate cancer: a preliminary report. Asia Pac J Clin Oncol. 2014;10(2):e46-e53.

24. Bernetich M, Oliai C, Lanciano R, et al. SBRT for the primary treatment of localized prostate cancer: the effect of gleason score, dose and heterogeneity of intermediate risk on outcome utilizing 2.2014 NCCN risk stratification guidelines. Front Oncol. 2014;4:312.

25. Zaorsky NG, Li T, Devarajan K, Buyyounouski MK. Assessment of the American Joint Committee on Cancer staging (sixth and seventh editions) for clinically localized prostate cancer treated with external beam radiotherapy and comparison with the National Comprehensive Cancer Network risk-stratification method. Cancer. 2012;118(22): $5535-5543$.

26. Zaorsky NG, Egleston B, Horwitz EM, et al. The Missing Pieces in Reporting of Randomized Controlled Trials of External Beam Radiation Therapy Dose Escalation for Prostate Cancer. Am J Clin Oncol. 2016 Jun 17. [Epub ahead of print] PMID: 27322694

27. Zaorsky NG, Shaikh T, Murphy CT, et al. Comparison of outcomes and toxicities among radiation therapy treatment options for prostate cancer. Cancer Treat Rev. 2016;48:50-60.

28. Zaorsky NG, Doyle LA, Yamoah K, et al. High dose rate brachytherapy boost for prostate cancer: a systematic review. Cancer Treat Rev. 2014;40(3):414-425.

29. Zaorsky NG, Hurwitz MD, Dicker AP, Showalter TN, Den RB. Is robotic arm stereotactic body radiation therapy "virtual high dose rate brachytherapy" for prostate cancer? An analysis of comparative effectiveness using published data [corrected]. Expert Rev Med Devices. 2015;12(3):317-327.

30. Zaorsky NG, Doyle LA, Hurwitz MD, Dicker AP, Den RB. Do theoretical potential and advanced technology justify the use of high-dose rate brachytherapy as monotherapy for prostate cancer? Expert Rev Anticancer Ther. 2014;14(1):39-50.

31. Zaorsky NG, Hallman MA, Smaldone MC. Radiation therapy to the primary tumor in locally advanced prostate cancer is not "closing the barn door after the horse has bolted". Ann Transl Med. 2015;3(18):274.

32. Zaorsky NG, Trabulsi EJ, Lin J, Den RB. Multimodality therapy for patients with high-risk prostate cancer: current status and future directions. Semin Oncol. 2013;40(3):308-321.

33. Dandapani SV, Sanda MG. Measuring health-related quality of life consequences from primary treatment for early-stage prostate cancer. Semin Radiat Oncol. 2008;18(1):67-72.

34. Kuban DA, Tucker SL, Dong L, et al. Long-term results of the M. D. Anderson randomized dose-escalation trial for prostate cancer. Int $J$ Radiat Oncol Biol Phys. 2008;70(1):67-74.

35. Al-Mamgani A, van Putten WL, Heemsbergen WD, et al. Update of Dutch multicenter dose-escalation trial of radiotherapy for localized prostate cancer. Int J Radiat Oncol Biol Phys. 2008;72(4):980-988.

36. Zietman AL, Bae K, Slater JD, et al. Randomized trial comparing conventional-dose with high-dose conformal radiation therapy in earlystage adenocarcinoma of the prostate: long-term results from Proton Radiation Oncology Group/American College of Radiology 95-09. J Clin Oncol. 2010;28(7):1106-1111. 
37. Dearnaley DP, Sydes MR, Graham JD, et al. Escalated-dose versus standard-dose conformal radiotherapy in prostate cancer: first results from the MRC RT01 randomised controlled trial. Lancet Oncol. 2007;8(6):475-487.

38. Michalski J, Winter K, Roach M, et al. Clinical outcome of patients treated with 3D conformal radiation therapy (3D-CRT) for prostate cancer on RTOG 9406. Int J Radiat Oncol Biol Phys. 2012;83(3):e363-e370.

39. Beckendorf V, Guerif S, Le Prisé E, et al. 70 Gy versus 80 Gy in localized prostate cancer: 5-year results of GETUG 06 randomized trial. Int J Radiat Oncol Biol Phys. 2011;80(4):1056-1063.

40. Miralbell R, Roberts SA, Zubizarreta E, Hendry JH. Dose-fractionation sensitivity of prostate cancer deduced from radiotherapy outcomes of 5,969 patients in seven international institutional datasets: $\alpha / \beta=1.4$ (0.9-2.2) Gy. Int J Radiat Oncol Biol Phys. 2012;82(1):e17-e24.

41. Fowler J, Chappell R, Ritter M. Is $\alpha / \beta$ for prostate tumors really low? Int J Radiat Oncol Biol Phys. Jul 15 2001;50(4):1021-1031.

42. Fowler JF, Ritter MA, Chappell RJ, Brenner DJ. What hypofractionated protocols should be tested for prostate cancer? Int J Radiat Oncol Biol Phys. 2003;56(4):1093-1104.

43. Brenner DJ, Martinez AA, Edmundson GK, Mitchell C, Thames HD, Armour EP. Direct evidence that prostate tumors show high sensitivity to fractionation (low $\alpha / \beta$ ratio), similar to late-responding normal tissue. Int J Radiat Oncol Biol Phys. 2002;52(1):6-13.

44. Park C, Papiez L, Zhang S, Story M, Timmerman RD. Universal survival curve and single fraction equivalent dose: useful tools in understanding potency of ablative radiotherapy. Int J Radiat Oncol Biol Phys. 2008;70(3):847-852.

45. Kolesnick R, Fuks Z. Radiation and ceramide-induced apoptosis. Oncogene. 2003;22(37):5897-5906.

46. Thames HD, Kuban D, Levy LB, et al. The role of overall treatment time in the outcome of radiotherapy of prostate cancer: an analysis of biochemical failure in 4839 men treated between 1987 and 1995 . Radiother Oncol. 2010;96(1):6-12.

47. Fuller DB, Naitoh J, Lee C, Hardy S, Jin H. Virtual HDR CyberKnife treatment for localized prostatic carcinoma: dosimetry comparison with HDR brachytherapy and preliminary clinical observations. Int J Radiat Oncol Biol Phys. 2008;70(5):1588-1597.

48. Hossain S, Xia P, Chuang C, et al. Simulated real time image guided intrafraction tracking-delivery for hypofractionated prostate IMRT. Med Phys. 2008;35(9):4041-4048.

49. Munoz F, Fiandra C, Franco P, et al. Tracking target position variability using intraprostatic fiducial markers and electronic portal imaging in prostate cancer radiotherapy. Radiol Med. 2012;117(6):1057-1070.

50. Wierzbicki M, Schaly B, Peters T, Barnett R. Automatic image guidance for prostate IMRT using low dose CBCT. Med Phys. 2010;37(7): 3677-3686.

51. Klayton T, Price R, Buyyounouski MK, et al. Prostate bed motion during intensity-modulated radiotherapy treatment. Int J Radiat Oncol Biol Phys. 2012;84(1):130-136.

52. Cavalieri R, Gay HA, Liu J, et al. Total error shift patterns for daily CT on rails image-guided radiotherapy to the prostate bed. Radiat Oncol. 2011;6:142.

53. Willoughby TR, Kupelian PA, Pouliot J, et al. Target localization and real-time tracking using the Calypso 4D localization system in patients with localized prostate cancer. Int J Radiat Oncol Biol Phys. 2006;65(2): 528-534.

54. Oliai C, Lanciano R, Sprandio B, et al. Stereotactic body radiation therapy for the primary treatment of localized prostate cancer. J Radiat Oncol. 2013;2(1):63-70.

55. Radiation Therapy Oncology Group. Radiation therapy in treating patients with prostate cancer. Available from: https:/clinicaltrials.gov/ ct2/show/NCT01434290. NLM identifier: NCT01434290. Accessed June 7, 2016.

56. Litzenberg DW, Balter JM, Hadley SW, et al. Prostate intrafraction translation margins for real-time monitoring and correction strategies. Prostate Cancer. 2012;2012:130579.
57. Holmboe ES, Concato J. Treatment decisions for localized prostate cancer: asking men what's important. J Gen Intern Med. 2000;15(10): 694-701.

58. Parthan A, Pruttivarasin N, Taylor D, et al. CyberKnife for prostate cancer: Is it cost-effective? J Clin Oncol. 2011;29 Suppl 7:87.

59. Perez CA, Kobeissi B, Smith BD, et al. Cost accounting in radiation oncology: a computer-based model for reimbursement. Int J Radiat Oncol Biol Phys. 1993;25(5):895-906.

60. Lievens Y, van den Bogaert W, Kesteloot K. Activity-based costing: a practical model for cost calculation in radiotherapy. Int J Radiat Oncol Biol Phys. 2003;57(2):522-535.

61. Norlund A. Costs of radiotherapy. Acta Oncol. 2003;42(5-6):411-415.

62. Kesteloot K, Lievens Y, van der Schueren E. Improved management of radiotherapy departments through accurate cost data. Radiother Oncol. 2000;55(3):251-262.

63. Van de Werf E, Lievens Y, Verstraete J, Pauwels K, Van den Bogaert W. Time and motion study of radiotherapy delivery: economic burden of increased quality assurance and IMRT. Radiother Oncol. 2009;93(1): 137-140.

64. Shah C, Lanni TB Jr, Ghilezan MI, et al. Brachytherapy provides comparable outcomes and improved cost-effectiveness in the treatment of low/intermediate prostate cancer. Brachytherapy. 2012;11(6): $441-445$.

65. Sher DJ, Parikh RB, Mays-Jackson S, Punglia RS. Cost-effectiveness analysis of SBRT versus IMRT for low-risk prostate cancer. Am J Clin Oncol. 2014;37(3):215-221.

66. Hodges JC, Lotan Y, Boike TP, Benton R, Barrier A, Timmerman RD. Cost-effectiveness analysis of stereotactic body radiation therapy versus intensity-modulated radiation therapy: an emerging initial radiation treatment option for organ-confined prostate cancer. J Oncol Pract. 2012;8(3 Suppl):e31s-37s.

67. Centers for Medicare \& Medicaid Services. Physician fee schedule. 2012. Available from: https:/www.cms.gov/Medicare/Medicare-Feefor-Service-Payment/PhysicianFeeSched/PFS-Carrier-Specific-FilesItems/CMS1254049.html. Accessed August 14, 2015.

68. Sharieff W, Greenspoon JN, Dayes I, Chow T, Wright J, Lukka H. The technique, resources and costs of stereotactic body radiotherapy of prostate cancer: a comparison of dose regimens and delivery systems. Technol Cancer Res Treat. 2016;15(1):171-178.

69. Kim DW, Straka C, Cho LC, Timmerman RD. Stereotactic body radiation therapy for prostate cancer: review of experience of a multicenter phase I/II dose-escalation study. Front Oncol. 2014;4:319.

70. National Comprehensive Cancer Network. NCCN clinical practice guidelines in oncology. 2015. Available from: https://www.nccn.org/ professionals/physician_gls/f_guidelines_nojava.asp. Accessed June 7, 2016.

71. Zaorsky NG, Raj GV, Trabulsi EJ, Lin J, Den RB. The dilemma of a rising prostate-specific antigen level after local therapy: what are our options? Semin Oncol. 2013;40(3):322-336.

72. Zaorsky NG, Yamoah K, Thakur ML, et al. A paradigm shift from anatomic to functional and molecular imaging in the detection of recurrent prostate cancer. Future Oncol. 2014;10(3):457-474.

73. Crawford ED, Black L, Eaddy M, Kruep EJ. A retrospective analysis illustrating the substantial clinical and economic burden of prostate cancer. Prostate Cancer Prostatic Dis. 2010;13(2):162-167.

74. Benedict SH, Yenice KM, Followill D, et al. Stereotactic body radiation therapy: the report of AAPM Task Group 101. Med Phys. 2010;37(8):4078-4101.

75. Yoshida K, Yamazaki H, Nakamara S, et al. Comparison of common terminology criteria for adverse events v3.0 and radiation therapy oncology group toxicity score system after high-dose-rate interstitial brachytherapy as monotherapy for prostate cancer. Anticancer Res. 2014; 34(4):2015-2018.

76. Janowski E, Chen LN, Kim JS, et al. Stereotactic body radiation therapy (SBRT) for prostate cancer in men with large prostates $\left(\geq 50 \mathrm{~cm}^{3}\right)$. Radiat Oncol. 2014;9:241. 
77. Potters L, Kavanagh B, Galvin JM, et al. American Society for Therapeutic Radiology and Oncology (ASTRO) and American College of Radiology (ACR) practice guideline for the performance of stereotactic body radiation therapy. Int J Radiat Oncol Biol Phys. 2010;76(2):326-332.

78. Kleinmann N, Zaorsky NG, Showalter TN, Gomella LG, Lallas CD, Trabulsi EJ. The effect of ethnicity and sexual preference on prostatecancer-related quality of life. Nat Rev Urol. 2012;9(5):258-265.

79. Royal Marsden NHS Foundation Trust. Prostate advances in comparative evidence (PACE). Available from: https://clinicaltrials.gov/ct2/show/ NCT01584258. NLM identifier: NCT01584258. Accessed June 7, 2016.

80. Zaorsky NG, Palmer JD, Hurwitz MD, Keith SW, Dicker AP, Den RB. What is the ideal radiotherapy dose to treat prostate cancer? A metaanalysis of biologically equivalent dose escalation. Radiother Oncol. 2015;115(3):295-300.

81. Zaorsky NG, Keith SW, Shaikh T, et al. Impact of radiation therapy dose escalation on prostate cancer outcomes and toxicities. Am J Clin Oncol. Epub 2016 Mar 24.
82. Boike TP, Lotan Y, Cho LC, et al. Phase I dose-escalation study of stereotactic body radiation therapy for low- and intermediate-risk prostate cancer. J Clin Oncol. 2011;29(15):2020-2026.

83. Meng MB, Wang HH, Zaorsky NG, et al. Clinical evaluation of stereotactic radiation therapy for recurrent or second primary mediastinal lymph node metastases originating from non-small cell lung cancer. Oncotarget. 2015;20;6(17):15690-15703.

84. Zaorsky NG, Den RB, Doyle LA, Dicker AP, Hurwitz MD. Combining theoretical potential and advanced technology in high-dose rate brachytherapy boost therapy for prostate cancer. Expert Rev Med Devices. 2013;10(6):751-763.

85. Wang HH, Zaorsky NG, Meng MB et al. Stereotactic radiation therapy for oligometastases or oligorecurrence within mediastinal lymph nodes. Oncotarget. Epub 2016 Feb 23.

86. Wang LS, Murphy CT, Ruth K et al. Impact of obesity on outcomes after definitive dose-escalated intensity-modulated radiotherapy for localized prostate cancer. Cancer. 2015;121(17):3010-3017. 


\section{Supplementary materials}
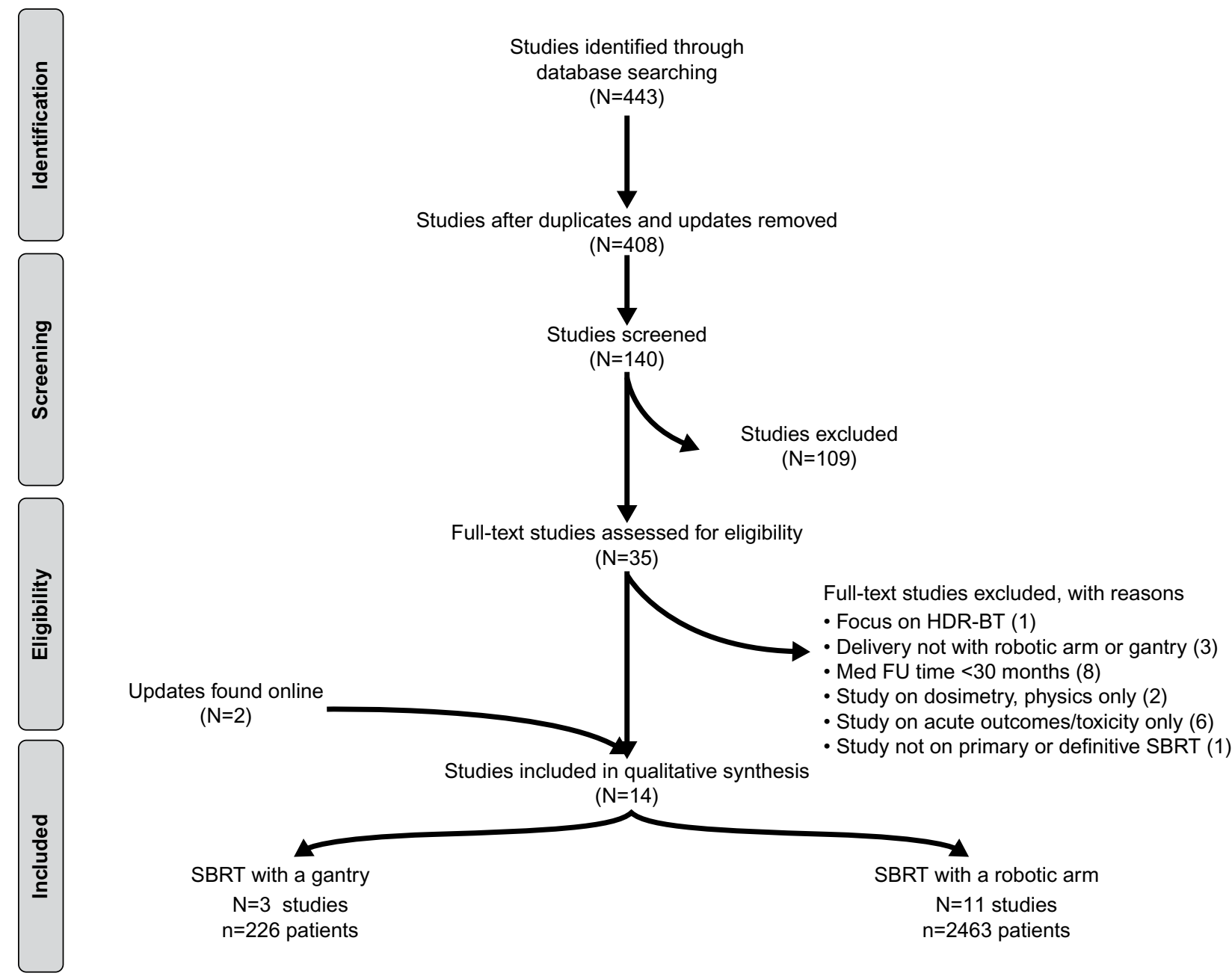

Studies included in qualitative synthesis

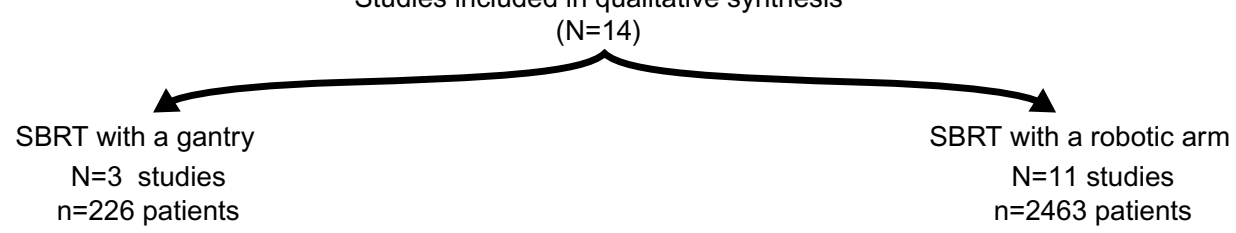

Figure SI PRISMA flow diagram of literature-selection process.

Abbreviations: FU, follow-up; HDR-BT, high-dose-rate brachytherapy; PRISMA, Preferred Reporting Items for Systematic Reviews and Meta-Analyses; SBRT, stereotactic body radiation therapy

Table SI PICOS approach and inclusion criteria

\begin{tabular}{|c|c|}
\hline Population & Men with localized (TI-T2, N0-Nx, M0) and locally advanced (T3-T4, N0-Nx, M0) prostate cancer \\
\hline Intervention & $\begin{array}{l}\text { SBRT monotherapy, defined as a single 6-15 Gy fraction lasting up to } 45 \text { minutes per day, for a total of up to five treatments, over } \\
\text { approximately } 2 \text { weeks, either on a robotic arm or a gantry LINAC }\end{array}$ \\
\hline Control & Either no control group (ie, single-arm study) or a multiarm study that may also contain the intervention \\
\hline \multicolumn{2}{|l|}{ Outcomes } \\
\hline Efficacy & Clinical (surrogate outcomes) for all studies: PSA kinetics, FFBF as defined by ASTRO or Phoenix definitions \\
\hline Safety & Late RTOG or CTCAE GU, GI toxicities \\
\hline \multicolumn{2}{|c|}{ Study design } \\
\hline Efficacy & All prospective and retrospective studies, $\geq 25$ patients, with one or more arms, $>30$-month FU \\
\hline Safety & All prospective and retrospective studies, $\geq 25$ patients, with one or more arms, $>30$-month FU \\
\hline
\end{tabular}

Abbreviations: ASTRO, American Society of Therapeutic Radiology and Oncology; CTCAE, Common Terminology Criteria for Adverse Events; FFBF, freedom from biochemical failure; FU, follow-up; GI, gastrointestinal; GU, genitourinary; LINAC, linear accelerator; PICOS, population, intervention, control, outcome, study design; PSA, prostate-specific antigen; RTOG, Radiation Therapy Oncology Group; SBRT, stereotactic body radiation therapy. 


\section{Publish your work in this journal}

Research and Reports in Urology is an international, peer-reviewed, open access journal publishing original research, reports, editorials, reviews and commentaries on all aspects of adult and pediatric urology in the clinic and laboratory including the following topics: Pathology, pathophysiology of urological disease; Investigation and treatment of urological disease; Pharmacology of drugs used for the treatment of urological disease. The manuscript management system is completely online and includes a very quick and fair peer-review system, which is all easy to use. Visit http://www.dovepress.com/testimonials.php to read real quotes from published authors.

Submit your manuscript here: https://www.dovepress.com/research-and-reports-in-urology-journal 